\title{
The effects of $17 \beta$-estradiol in cancer are mediated by estrogen receptor signaling at the plasma membrane
}

\section{Filippo Acconcia and Maria Marino*}

Cell Physiology Laboratory, Department of Biology, University Roma Tre, Rome, Italy

\section{Edited by:}

Ali Mobasheri, The University of

Nottingham, UK

\section{Reviewed by:}

Paul G. Mermelstein, University of

Minnesota, USA

Dimitra Mangoura, Biomedical

Research Foundation of the Academy

of Athens, Greece

\section{${ }^{*}$ Correspondence:}

Maria Marino, Department of Biology, University Roma Tre, Viale Guglielmo Marconi 446, I-00146 Rome, Italy.

e-mail:m.marino@uniroma3.it
Two different isoforms of the estrogen receptors (i.e., ER $\alpha$ and ER $\beta$ ) mediate pleiotropic $17 \beta$ estradiol (E2)-induced cellular effects. The ERs are principally localized in the nucleus where they act by globally modifying the expression of the E2-target genes. The premise that E2 effects are exclusively mediated through the nuclear localized ERs has been rendered obsolete by research over the last 15 years demonstrating that $E R \alpha$ and $E R \beta$ proteins are also localized at the plasma membranes and in other extra-nuclear organelles. The E2 modulation of cancer cell proliferation represents a good example of the impact of membrane-initiated signals on E2 effects. In fact, E2 via ER $\alpha$ elicits rapid signals driving cancer cells to proliferation (e.g., in breast cancer cells), while E2-induced ER $\beta$ rapid signaling inhibits proliferation (e.g., in colon cancer cells). In this review we provide with an overview of the complex system of E2-induced signal transduction pathways, their impact on E2-induced cancer cell proliferation, and the participation of E2-induced membrane-initiated signals in tumor environment.

Keywords: estrogens, estrogen receptors, membrane-initiated signals, cell proliferation, cell apoptosis

\section{INTRODUCTION}

$17 \beta$-estradiol (E2), the most effective female estrogen, is critical for the control of a plethora of biological responses that strongly influence several aspects of male and female physiology. Thus, it is not surprising that $\mathrm{E} 2$ and its estrogen receptors (i.e., $\mathrm{ER} \alpha$ and $\mathrm{ER} \beta$ ) are also considered to be risk factors for the initiation and progression of several endocrine-related cancers (e.g., breast, prostate, ovarian, and endometrial cancer; Deroo and Korach, 2006). However, the E2 effects on cancer are often divergent and somewhat contrasting depending on the relative levels of the ER subtypes in a given cancer cell. These contrasting effects relate to the spectacular complexity of the E2 intracellular signaling triggered by the ERs.

The two ER subtypes are activated when the hormone binds to the ligand-binding domain (LBD) of the receptors. Upon binding, several events occur, such as overall conformational changes of receptors, receptor dimerization, nuclear translocation, and binding to specific estrogen response elements (ERE) on DNA. Ligand-binding favors the receptor interaction with coregulators (i.e., co-activators and corepressors), which are chromatin remodelers that are essential for E2-induced gene transcription (Ascenzi et al., 2006; Nalvarte et al., 2010; Nilsson and Gustafsson, 2011).

However, the effects of E2 can have a rapid onset. These effects, mediated by membrane-localized ER $\alpha$ and ER $\beta$, also occur in tumor environments. Indeed, in cultured cancer cells, membraneinitiated $\mathrm{ER} \alpha$ signaling mediates the proliferative effects of E2 (Acconcia et al., 2005a; Ascenzi et al., 2006; Marino and Ascenzi, 2008), whereas membrane-initiated ER $\beta$ signaling directs the antiproliferative effects of E2 (Galluzzo et al., 2007; Marino and Ascenzi, 2008). In addition, specific ER $\alpha$ splice variants and interactors, which hyperstimulate extra-nuclear $\mathrm{ER} \alpha$ signaling, are over-expressed in aggressive and metastatic breast tumors (Kumar et al., 2002; Ohshiro et al., 2010). Moreover, the progressive reduction in $\operatorname{ER} \beta$ expression correlates with an increased $\mathrm{ER} \alpha-$ mediated cell proliferation in breast cancer cells (Paruthiyil et al., 2004) and uncontrolled colon cell proliferation (Galluzzo et al., 2007; Barone et al., 2010; Warner and Gustafsson, 2010). Nonetheless, the role of the membrane-initiated ER signaling in tumors has been underestimated and, at the present, nuclear ERs localization (Kumar, 2003; Barone et al., 2010) is considered as both a negative and positive prognostic factor. The bias concerning the application of ER membrane-initiated mechanism(s) as tool in cancer diagnosis and therapies likely results from experimental evidence obtained exclusively from in vitro model systems. Thus, the lack of an in vivo model (i.e., in animal models) questions the physiological relevance for these E2-triggered effects. However, recently, Shaul and co-workers (Chambliss et al., 2010) showed for the first time that the E2-induced membrane-initiated signals occur in mice independently of the genomic ER-dependent mechanism.

Therefore, the role of extra-nuclear E2 signaling in the context of a transformed cell (i.e., cancer) needs to be re-evaluated. In this review, we will give an overview of the complex system of E2-induced signal transduction pathways, their impact on E2-induced cancer cell proliferation, and the participation of E2-induced membrane-initiated signals in tumor environment.

\section{THE STRUCTURE OF THE ESTROGEN RECEPTORS}

The ER $\alpha$ and the ER $\beta$ are ligand-activated nuclear receptors, which have a high degree of sequence homology and a similar three-dimensional structure. In particular, the ERs are modular proteins composed of six functional domains. Each domain has autonomous functions: the $\mathrm{N}$-terminal portion (A/B domain) plays a role in protein-protein interactions and in the activation of gene transcription; the DNA binding domain (DBD), also known as the $\mathrm{C}$ domain, directs receptor dimerization and binding to 
DNA in the gene promoters containing the ERE; the D domain, which works as an hinge and also contributes to receptor dimerization, is the binding site for the heat-shock proteins (Hsp); and the C-terminal domain contains the LBD or E domain, which is now recognized to bind $\mathrm{E} 2$ and to cooperate with the $\mathrm{A} / \mathrm{B}$ domain in synchronizing gene transcription. Although the function of the $\mathrm{C}$ terminal portion of the receptor still remains obscure, the so-called F domain can also modulate ER transcriptional activity (Ascenzi et al., 2006).

Two distinct transcription activation functions (AFs) have been identified for the ERs. The AF-1 region is localized within the Nterminal portion (A/B domain) and is able to regulate ERE-based gene transcription, even in the absence of ligand. Furthermore, the C-terminal AF-2 region mediates ligand-dependent transcriptional activation by E2. Interestingly, both AFs coordinate gene transcription by dictating the pattern of association of the ERs with either co-activators or corepressors (Lonard and O'Malley, 2007; O'Malley and Kumar, 2009). In addition to E2, the ERs can bind to diverse natural and synthetic molecules, which are now considered to be exogenous ERs ligands [e.g., selective estrogen receptor modulators (SERMs), endocrine disruptors; Ascenzi et al., 2006]. Notably, the use of these ligands led to the definition of the ERs as highly allosteric proteins and offered the opportunity to design drugs that target the ERs in the treatment of E2-related diseases, such as cancer (Ascenzi et al., 2006).

In addition to full-length ERs, numerous truncated forms of the ER exist, resulting from alternative mRNA splicing; these ERs have been found in a number of normal and pathological tissues and are frequently co-expressed with their full-length counterparts. Moreover, ER degradation peptides (e.g., ER $\alpha 17$ p) have also been discovered (Pelekanou et al., 2011). The exact function and potential physiological role of the truncated forms and receptor fragments of $E R \alpha$ and $E R \beta$ in human disease remain to be elucidated (Ascenzi et al., 2006; Herynk and Fuqua, 2004), but evidence indicates that these shorter ERs (e.g., ER $\alpha 36$; ER $\alpha V$; ERa46; ER $\beta c x$; ER $\alpha$ p17) can differentially modulate E2 signaling, impact target gene regulation and, consequently, be involved in tumor growth and progression (Li et al., 2003; Penot et al., 2005; Wang et al., 2005, 2006; Koduri et al., 2006; Galluzzo et al., 2007; Lee et al., 2008; Ohshiro et al., 2010; Pelekanou et al., 2011).

\section{ESTROGEN RECEPTOR-BASED SIGNAL TRANSDUCTION}

The initial cloning of ER $\alpha$ (Green et al., 1986; Greene et al., 1986) and ER $\beta$ (Kuiper et al., 1996; Gustafsson, 1999) has led to changes in the interpretation of the E2 molecular mechanism. Thus, it is now known that both ER isoforms share the same molecular action mechanisms (Ascenzi et al., 2006).

$\mathrm{ER} \alpha$ and $\mathrm{ER} \beta$ are transcription factors that directly bind DNA to regulate gene transcription (i.e., direct genomic mechanism). The regulation of gene transcription occurs by receptor cycling on and off their DNA binding sites (i.e., ERE sequence). The binding of E2 stabilizes these transient receptor: DNA complexes making possible mRNA production (Métivier et al., 2003; Reid et al., 2003; Picard et al., 2008).

ERs mediate transcription via tethered interactions through protein-protein interactions with other transcription factors [e.g., activating protein-1 (AP-1), stimulating protein-1 (Sp1)] to activate gene expression (i.e., indirect genomic mechanism; Ascenzi et al., 2006).

Both $\mathrm{ER} \alpha$ and $\mathrm{ER} \beta$ are membrane-tethered proteins. The membrane localization of the ERs allows the occurrence of the rapid effects of E2 (i.e., extra-nuclear mechanism; Hammes and Levin, 2007; Marino and Ascenzi, 2008).

Therefore, E2 molecular mechanisms are strictly dependent on the intracellular localization of the ERs. However, it should be noted that although both the nuclear and membrane-initiated ER activities can be studied independently, the cognate hormone E2 triggers both of these activities. Thus, both ER activities must occur simultaneously and be intertwined in vivo. In turn, the de-regulation of one of either nuclear or membrane-initiated ER activities will irremediably impact the other, with potential pathological consequences. The challenge is to understand the molecular details that allow their synergy. The post-translational modifications of $E R \alpha$ and ER $\beta$ and the selective association of the ERs with specific interactors appears to be a mechanism for cells to finely tune and integrate nuclear and extra-nuclear ER signaling (Marino and Ascenzi, 2008; La Rosa et al., 2011).

\section{THE GENOMIC MECHANISM}

It is a well-known fact that in ER-expressing cells, the nonactivated ERs are associated in the cytoplasm with the Hsp (e.g., Hsp90, Hsp70, and Hsp56). Upon E2 binding, allosteric transitions occur in the ER, the Hsps dissociate and the receptors translocate to the nucleus, where ERE-based gene transcription occurs by recruiting cofactor proteins (i.e., co-activators and corepressors), and the basal transcription machinery (Kumar and Chambon, 1988; McKenna and O’Malley, 2001; Ascenzi et al., 2006; Lonard and O'Malley, 2007; O’Malley and Kumar, 2009). The co-activators interact with the ERs through their leucine(L)-rich motifs (i.e., LXXLL, where $\mathrm{X}$ is any amino acid; e.g., SRC-1) and facilitate ER transcriptional activity by triggering chromatin remodeling (e.g., CBP/p300 PRMT1, SWI/SNF), RNA polymerase II activation, and linking the ERs to the basal transcription machinery (Ascenzi et al., 2006), whereas corepressors [e.g., histone deacetylases (HDAC)] prevent ERs from inducing gene transcription (Jepsen and Rosenfeld, 2002).

In the nucleus, $\mathrm{ER} \alpha$ cycles on and off the ERE-containing gene promoters. Although this process occurs even in the absence of E2, E2 shifts these coordinated and transcriptionally unproductive $\mathrm{ER} \alpha-\mathrm{DNA}$ association/dissociation cycles toward a productive transcriptional response (Métivier et al., 2003; Reid et al., 2003). Interestingly, the discovery that E2-activated ER $\beta$ possesses a similar cyclic nature (Picard et al., 2008) indicates that this molecular circuitry is conserved. Therefore, the de-regulation of any step of the transcriptional cycle (e.g., alteration in ER: co-activators interaction) could lead to malignant transformation (Lonard and O'Malley, 2006).

In addition to direct interaction with ERE, ERs can regulate gene transcription without directly binding to DNA. In this indirect genomic mechanism, $\mathrm{ER} \alpha$ associates with specific transcription factors, such as Sp1 and AP-1, which play an important role in the transcriptional activation of multiple growth regulatory genes in breast cancer cells. $\mathrm{ER} \beta / \mathrm{Sp} 1$ is primarily associated with decreased ligand-dependent gene expression 
(Safe, 2001; Pearce and Jordan, 2004). The interaction between ERs and nuclear factor- $\kappa \mathrm{B}$ induces the E2-mediated inhibition of gene transcription (Ascenzi et al., 2006).

\section{THE EXTRA-NUCLEAR MECHANISM}

The nuclear actions of E2 occur after at least 2-h time lag postE2 stimulation (Métivier et al., 2003; Reid et al., 2003) and explain some E2 functions in physiological and pathological situations (see Farach-Carson and Davis, 2003; Ascenzi et al., 2006). However, E2 elicits some cellular effects that are too rapid (i.e., in seconds to minutes) to be mediated by the activation of the nuclear ERs (Szego and Davis, 1967). These effects are refractory to transcription and translation inhibitors (Losel et al., 2003) and are induced by membrane-impermeable E2 conjugates (e.g., E2-BSA; Ascenzi et al., 2006). The E2-evoked rapid signals involve the activation of several signal transduction pathways (e.g., phospholipase C (PLC)/protein kinase C (PKC); Src/extracellular-activated kinase (ERK), phosphatidyl-inositol 3 kinase (PI3K)/AKT, p38/mitogenactivated protein kinase (MAPK); Janus kinase/signal transducers and activators of transcription (JAK/STAT); p21-activated kinase 1 (Pak1); casein kinase I-g2; sphingosine kinase; RhoA/ROCK2/moesin; Losel et al., 2003; Ascenzi et al., 2006; Hammes and Levin, 2007; Sanchez et al., 2009) in E2-sensitive cells, and some of these signaling pathways could be cell type specific. Interestingly, both $E R \alpha$ and $E R \beta$ trigger the activation of the rapid E2-induced effects although there appears to be some degree of specificity in the isoform-mediated extra-nuclear signaling.

Remarkably, accumulating evidence identifies at least two conserved pathways in membrane ER $\alpha$-based E2 rapid signaling. The E2-dependent activation of the ERK component of the MAPK family and the AKT kinase in the PI3K axis occur in a variety of normal or transformed cell lines (e.g., vascular or epithelial cells; breast cancer cell; hepatoma cells). The mechanism by which the E2-ER $\alpha$ complex activates these two transduction pathways involves the E2-induced association of membrane $\mathrm{ER} \alpha$ with several proteins involved in the ERK/MAPK pathway (i.e., Shc, Src, Ras) leading to Shc/Src/Ras/ERK activation (Song et al., 2004) and the PI3K/AKT pathway [i.e., p85, integrin-linked kinase (ILK), glycogen synthase kinase $3 \beta$ (GSK3 $\beta$ )] leading to $\mathrm{PI} 3 \mathrm{~K} / \mathrm{ILK} / \mathrm{AKT} / \mathrm{GSK} 3 \beta$ activation and nitric oxide (NO) release (Simoncini et al., 2000; Medunjanin et al., 2005; Acconcia et al., 2006). Interestingly, in cancer cells either signaling cascade transduces the E2 proliferative and anti-apoptotic effects by modulating E2-induced DNA synthesis, resulting in cell cycle progression and cell proliferation (Marino et al., 2002, 2003; Song et al., 2004) as well as cell migration (Acconcia et al., 2006).

The ability of the E2-ER $\beta$ complex to activate rapid extranuclear mechanisms has received less consideration. Our work identified the E2-dependent activation of the p38 component of the MAPK family as a conserved pathway in membrane ER $\beta$-based E2 rapid signaling. Indeed, the E2-induced ER $\beta$-mediated activation of the p38/MAPK occurs in ER $\beta$-transfected HeLa cells and in $\operatorname{ER} \beta$ containing rat myoblasts, colon adenocarcinoma cells, and neuroblastoma cells (Acconcia et al., 2005a; Galluzzo et al., 2007, 2009; De Marinis et al., 2010). In any case, the E2-dependent activation of the $\mathrm{p} 38 / \mathrm{MAPK}$ pathway requires the physical association between membrane ER $\beta$ and p38 and results in triggering the E2 anti-proliferative and pro-apoptotic effects in colon cancer cell lines (Galluzzo et al., 2007).

The data reported here strongly demonstrate that the membrane-initiated effects of E2 can regulate different and opposite cellular processes, such as proliferation, survival, apoptosis, and are operative in transformed and malignant cells. Moreover, they represent conserved molecular circuitries by which E2 exerts its pleiotropic effects through the $\mathrm{ER} \alpha$ and the ER $\beta$. In turn, the de-regulation of ER $\alpha$ - and ER $\beta$-mediated rapid signal transduction would lead to pathological consequences, such as cancer. In this respect, it is noteworthy that $\mathrm{ER} \alpha$-positive breast tumors are treated with drugs aimed at interfering with the availability of endogenous E2 (e.g., aromatase inhibitors) or ER $\alpha$ transcriptional activity (e.g., 4OH-tamoxifen; Keen and Davidson, 2003). The same drugs also act on the ER $\beta$ rapid signaling, but not because $\mathrm{ER} \beta$ expression is inversely correlated with the development of several cancer (i.e., breast and colon cancer; Marino and Ascenzi, 2008; Barone et al., 2010; Warner and Gustafsson, 2010).

Therefore, one would expect this mechanism to be highly regarded as a target for cancer prevention or treatment. However, this is not the case most likely because of concerns about the way the membrane-initiated effects of E2 are elicited after E2-ER engagement.

Membrane localization of the estrogen receptors. The rapid ER signaling of the E2 requires an ER to be localized at the plasma membrane. Although more that 2000 publications dealing with membrane localization of ERs and rapid extra-nuclear effects of E2 appeared in scientific databases over the past 40 years, this area of research is highly debated. Accordingly, because ERs belong to a nuclear receptor superfamily, a dogmatic assumption dictates that the effects of E2 can be mediated exclusively through the transcriptional actions of the nuclear localized ER. This statement refers to some classic doubts about the reasons why cells would have evolved a mechanism to localize a nuclear receptor at the plasma membrane.

It is now accepted that ERs are localized at the plasma membrane of E2-sensitive cells. After the initial discovery in 1967 that E2 administration to an ovariectomized rat triggers the rapid increase (15s) in cAMP levels (Szego and Davis, 1967), specific plasma membrane binding sites for E2 were first identified in 1977 at the surface of endometrial cells (Pietras and Szego, 1977) and later, were also demonstrated at the breast cancer cell plasma membrane (Berthois et al., 1986). However, it was only in the late 90s that a panel of antibodies were created against multiple epitopes of nuclear ER $\alpha$ that were also able to recognize the membrane ER $\alpha$ (Pappas et al., 1995); antisense oligonucleotides directed against the nuclear ER $\alpha$ also caused a decrease in the expression of membrane ER $\alpha$ (Norfleet et al., 1999) and the ectopic expression of $\mathrm{ER} \alpha \mathrm{cDNA}$ in ER null cells resulted in both nuclear and membrane localization of ER $\alpha$ (Razandi et al., 1999). More recently, a protein of the same size of the recombinant $\mathrm{ER} \alpha$ was isolated from the breast cancer cell membrane, detected by ER $\alpha$ antibodies and then subjected to mass spectrometry. The peptides that resulted from tryptic digestion were scored as $100 \%$ identical to classical human ER $\alpha$ (Pedram et al., 2006). Therefore, the nuclear ER $\alpha$ is identified as the receptor form at the plasma membrane. 
Nonetheless, there is also accumulating evidence that E2 binds to other receptors belonging to an entirely different family of proteins. The G-protein-coupled and seven-transmembrane receptor, GPR30, is recognized to be an estrogen receptor (Prossnitz et al., 2008; Maggiolini and Picard, 2010), even if this assumption continues to be seriously disputed (Levin, 2009; Otto et al., 2009). GPR30 is widely expressed in carcinoma cell lines including ER-positive MCF-7 and ER-negative SK-Br3 breast cancer cells, endometrial cancer cells, ovarian cancer cells, and thyroid carcinoma cell lines (Maggiolini and Picard, 2010). Although these data suggest a connection of GPR30 to cancer, larger sample sizes with more measured parameters and patient follow-up are needed. In addition, the GPR30 gene has not emerged in gene expression signatures for aggressive breast cancer nor has it scored as a hit in functional screens for genes contributing to $4 \mathrm{OH}$-tamoxifen resistances in breast cancer cells (Maggiolini and Picard, 2010). Therefore, GPR30 signaling will not be analyzed here.

The fact that the amount of the ERs at the plasma membrane is approximately $5-10 \%$ of the endogenous ER cellular content has raised questions concerning the physiological importance of E2 rapid signals. Nonetheless, the membrane localization of ERs is necessary and sufficient for the activation of the E2 membraneinitiated signals because the inhibition of these membranemediated events prevents E2-triggered mitogenic, motile, and apoptotic responses (Acconcia et al., 2006; Hammes and Levin, 2007; Marino and Ascenzi, 2008). Moreover, it is interesting to note that upon E2 administration, only 5-10\% of the endogenous cellular ERs are activated (Leclercq et al., 1986). Thus, it is tempting to speculate that upon E2 binding, the membrane receptor signals and shuttles into the nucleus where it also triggers gene transcription. From an evolutionary standpoint, the presence of plasma membrane ERs would have given the selective advantage to rapidly respond to the changes in the concentration of the lipophilic hormone (i.e., E2) in the extra-cellular environment. This mechanism would avoid the necessity for E2 to directly engage the nuclear ER, which is shielded by two bilayer membranes. Although this process is inconsistent with the classic notion of E2 entry into target cells, which is known as the "free" hormone hypothesis (Adams, 2005), data regarding an active transport mechanism for E2 cellular uptake are accumulating (Pietras and Szego, 1984; Hammes et al., 2005). Moreover, the recent discovery that $\mathrm{E} 2$ is stably inserted into the plasma membrane and can flip within the lipid bilayer without escaping it (Scheidt et al., 2010) further supports the notion for an active transport mechanism for E2 internalization.

Interestingly, the ERs do not possess any intrinsic transmembrane domain, thus a great experimental effort was undertaken to understand the molecular determinants required for the membrane localization of the ERs. At present, three main mechanisms have been identified for the plasma membrane localization of ERs, including the association with resident membrane proteins, the interaction with transmembrane receptors and lipid modification.

Membrane $\operatorname{ER} \alpha$ and $\operatorname{ER} \beta$ are localized in caveolae (Razandi et al., 2002) or in other membrane raft structures (Márquez et al., 2006). The caveolae localization of the ERs is mediated by the direct physical interaction of ERs with caveolin-1. Indeed, cells lacking caveolin-1, but containing ERs, show only nuclear localization of the receptors. Consistent with this evidence, expression of exogenous caveolin-1 in this cell context results in a small population of ERs localizing at the plasma membrane (Razandi et al., 2003). The localization of ER $\alpha$ to non-caveolae lipid rafts was also recently shown to be dependent on a direct association of the receptor with the raft protein flotillin-2. Interestingly, this peculiar ER $\alpha$ raft localization appears to modulate downstream nuclear events leading to cell growth (Márquez et al., 2006).

Furthermore, the interaction of $\mathrm{ER} \alpha$ with specific membrane receptor tyrosine kinases, such as HER-2 (Yang et al., 2004) and IGF-1R (Song et al., 2004), is also a mechanism for the membrane localization of the ER $\alpha$. Interestingly, because ERs do not display any intrinsic kinase activity, the membrane association with growth factor receptors is thought to allow $\mathrm{ER} \alpha$ to recruit signaling molecules (e.g., p85) required for the activation of phosphorylation cascades (Marino and Ascenzi, 2008).

The palmitoylation (i.e., protein modification with palmitic acid) is a post-translational modification that directs full-length $\mathrm{ER} \alpha$ and $\mathrm{ER} \beta$ to the plasma membrane (Acconcia et al., 2005b; Galluzzo et al., 2007). The palmitoylation of $\mathrm{ER} \alpha$ and $\mathrm{ER} \beta$, which occurs within the $\mathrm{E}$ domain of the receptors, is required for receptor membrane localization and interaction with caveolin-1, activation of E2 rapid signaling, and the completion of the downstream physiological processes (Acconcia et al., 2005b, 2006; Galluzzo et al., 2007; Marino and Ascenzi, 2008).

However, the mechanism of the E2-dependent modulation of ER association with plasma membrane is still not completely understood. E2 induces the de-palmitoylation of both ER $\alpha$ and ER $\beta$ (Acconcia et al., 2005b; Galluzzo et al., 2007), but the subsequent downstream effects are different for $\operatorname{ER} \alpha$ and $\operatorname{ER} \beta$. Indeed, the E2-activated ER $\alpha$ dissociates from caveolin-1 and is re-located to other membrane proteins (i.e., HER-2 and IGF-1R; Song et al., 2004; Yang et al., 2004), whereas the E2-activated ER $\beta$ further associates with caveolin-1 and to the p38/MAPK (Galluzzo et al., 2007). Following E2-mediated de-palmitoylation, rapid ER $\alpha$ and ER $\beta$ signals occur and are required to induce E2-evoked cell proliferation (Acconcia et al., 2005b) or apoptosis (Galluzzo et al., 2007). Thus, while palmitoylation is critical to locate the ERs at the plasma membrane, the E2-dependent modulation of this posttranslational modification provides the basis for the differential effects of E2 as both an oncogenic molecule for breast cancer (i.e., $\mathrm{ER} \alpha$ signaling) and a protective factor for colon cancer (i.e., $\mathrm{ER} \beta$ signaling).

\section{ROLE OF THE MEMBRANE-INITIATED MECHANISMS IN TUMORS}

Only limited information is available concerning the occurrence of the aforementioned conserved molecular circuitries in vivo and thus, even less proof of their de-regulation in tumor samples is evident. Nonetheless, evidence that demonstrates the presence of the membrane-initiated E2 effects in vivo exists and can no longer be ignored. As a consequence, their importance in carcinogenesis needs to be re-evaluated.

\section{EVIDENCE FOR IN VIVO MEMBRANE-INITIATED E2 EFFECTS}

Careful inspection of the literature reveals that the discovery that E2 elicits rapid effects in vivo was reported (Szego and Davis, 
1967) soon after the formal definition that the sex steroid hormone E2 acts through a receptor protein (Jensen, 1965), but before the formulation of the concept that steroid hormones acted on DNA to regulate gene transcription (O'Malley and McGuire, 1968); the intravenous administration of physiological doses of $\mathrm{E} 2$ to ovariectomized rats induces within $15 \mathrm{~s}$ a dramatic increase of uterine cyclic AMP, which lasts for $5 \mathrm{~min}$ and is reduced to basal levels within $1 \mathrm{~h}$. Interestingly, these effects are mimicked by another estrogenic molecule (i.e., diethylstilbestrol) and are unaffected by $17 \alpha$-estradiol. The physiological relevance of this is apparent because there is early evidence of estrogenic stimulation, including the liberation of sequestered histamine and the accompanying expansion of the microcirculation and associated alterations in membrane functions (Szego and Davis, 1967).

When the multifaceted and intertwined nature of ERs signaling network was already known, the group of Dr Jameson Jakacka et al., 2002 created a mouse model in which a point mutation was created in the first zinc finger of the DBD of the endogenous $\mathrm{ER} \alpha$. This mutation (E207A/G208A in mouse ER $\alpha$ ) abolishes receptor to ERE binding and the activation of ERE-containing reporter genes, but preserves all the other ER $\alpha$-based signals (Jakacka et al., 2002; Pedram et al., 2009). The analysis of the phenotype for the ER knock-in mouse model revealed that the knock-in female mice are infertile; indeed, their ovaries did not contain any corpora lutea and the stromal cells contained abundant lipid droplets. In addition, the uteri were enlarged with a clear evidence of cystic endometrial hyperplasia, whereas the mammary glands were hypo-plastic (Jakacka et al., 2002). Because the ER $\alpha$ knock-in mice phenotypes were significantly different from the ER $\alpha$ knock-out mice phenotypes, the observed defects demonstrate the complexity of the E2 signaling in whole-animal physiology and highlight how the extra-nuclear ER $\alpha$ signaling modulates different E2dependent effects in different tissues. Interestingly, the alteration in the steroidogenesis (i.e., fat accumulation in ovary stromal cells) in the ER $\alpha$ knock-in mouse model is phenocopied by the accumulation of abdominal visceral and other depots of fat (i.e., overall increased body weight), which is observed in the transgenic mice expressing only a functional $\mathrm{E}$ domain of $\mathrm{ER} \alpha$ at the plasma membrane (Pedram et al., 2009). Thus, the fact that E2 determines such a dramatic imbalance in the female mice physiology by acting on ER $\alpha$, which is incapable to trigger ERE-mediated E2induced gene transcription, and on the E domain of the receptor, which is critical for extra-nuclear E2 signaling activation, further demonstrates the activity of the membrane-initiated ER $\alpha$ pathway in vivo (Jakacka et al., 2002; Pedram et al., 2009). Nonetheless, although both $\mathrm{ER} \alpha$ knock-in mice and transgenic $\mathrm{ER} \alpha \mathrm{E}$ domain mice retain the E2-induced activation of ERK/MAPK and AKT as the wild type counterparts, the analysis of their phenotype demonstrates that the nuclear $\mathrm{ER} \alpha$ is critical for normal development in mice (Jakacka et al., 2002; Pedram et al., 2009), thus confirming that there is both nuclear and membrane-initiated ER $\alpha$ signaling cross-talk in vivo. Unfortunately, none of these studies analyzed whether these animals were more or less prone to develop tumors. Considering that $\mathrm{ER} \alpha$ membrane-initiated signals are critical for DNA synthesis and cell cycle progression, one might expect an increased incidence in tumors in at least some E2-sensitive tissues.
Chambliss et al. (2010) recently used a more physiological approach to demonstrate that activation of rapid, membraneinitiated $\mathrm{ER} \alpha$ signals is important in vivo. The use of an E2dendrimer conjugate, that activates membrane-associated ERs, but excludes them from the nucleus (Harrington et al., 2006), revealed that, in vivo, the vascular protective effects of $\mathrm{E} 2$ are mediated exclusively through membrane-initiated $\mathrm{ER} \alpha$ signal pathways (Chambliss et al., 2010). These data are, of course, extremely important because they represent the first demonstration that extra-nuclear E2-mediated effects are operative in mice. In turn, this evidence gives the opportunity to pharmacologically target extra-nuclear E2 signaling in vivo through the development of extra-nuclear specific drugs. Nonetheless, the E2-dendrimer conjugates are synthetic and the presence of the dendrimer may render the interpretation of the data incomplete. For this reason, understanding how a non-membrane localized receptor (e.g., the palmitoylation-defective mutant) works in vivo under the stimulation of the physiological hormone remains a critical issue.

Finally, it is important to note here that an in vivo model in which the ER $\beta$ is manipulated to study its membrane-initiated signals is not available at the present. Moreover, caution should be used in the interpretation of the abovementioned data because they were all studied in an ER $\beta$-wild type background.

\section{EVIDENCE FOR EXTRA-NUCLEAR E2 EFFECTS IN CLINICAL PRACTICE}

As the emerging data concerning membrane ERs signaling facilitates our understanding of E2 actions, the integration of this information with the clinic-pathological data of patients becomes imperative. For the moment, only nuclear ERs localization tests are utilized in daily hospital practices to obtain predictive diagnosis and to choose pharmacological therapies.

However, at least for breast cancer, mounting evidence points to the expression of the membrane $\mathrm{ER} \alpha$ as a tumor exclusivity. In fact, the adjacent non-cancerous tissues are negative for membrane ER $\alpha$ (Kampa et al., 2008). Interestingly, the analysis of 219 primary breast cancers by immuno-histochemical staining reveals that membrane ER $\alpha$ is detected in $34 \%$ of the cases in which the tumor is classified as ER $\alpha$-negative on the basis of the ER $\alpha$ nuclear expression. Moreover, breast tumor samples, expressing membrane $\mathrm{ER} \alpha$, also display a positive correlation with phosphorylated AKT and HER-2 over-expression (Kim et al., 2006). Remarkably, another study reports that, in $\mathrm{ER} \alpha$-positive breast specimens derived from patients after surgical resection, the plasma membrane localized ER $\alpha$ is phosphorylated on the serine residue 118 (i.e., activated), whereas it is absent from normal breast tissue. The phosphorylated, membrane-bound ER appears to define the "invasive carcinoma state" in human fresh tissue specimens because the analysis of the downstream signaling pathways in the cytosol of the same samples shows an hyper-activated status of the signaling kinases ERK/MAPK and AKT, which is correlated with an increase in anti-apoptotic signals (Mintz et al., 2008). Furthermore, other phosphorylated forms of the ER $\alpha$ have been found in tumors but their correlation with membrane-initiated signaling was not studied (Murphy et al., 2011). Data concerning the expression of membrane ERs in tumor specimens are limited to $\mathrm{ER} \alpha$, while no studies for membrane $\mathrm{ER} \beta$ in tumor samples have been performed. 
Nonetheless, at present, the mechanism by which an increased fraction of the activated ER $\alpha$ is localized at the cell plasma membrane in the tumor cells is still not known. De-regulation of the enzyme that palmitoylates receptors may, however, account for it. In addition, activated ER $\alpha$ can be forced to localize outside the nucleus and/or in close proximity of the plasma membrane by virtue of the over-expression of some specific ER $\alpha$ interactors. The spliced form of the metastasis tumor antigen (MTA1s), the modulator of extra-nuclear activity of estrogen receptor (MNAR, also known as PELP1), and activated growth factor receptors are the prototype of such a protein (Acconcia and Kumar, 2006). Indeed, MTA1s sequesters the ER $\alpha$ in the cytoplasm, is highly expressed in $\mathrm{ER} \alpha$-negative but not in $\mathrm{ER} \alpha$ positive breast tumors, and an increased level of MTA1s in $\mathrm{ER} \alpha$-nuclear negative tumors is associated with the presence of cytoplasmic ER $\alpha$ in tumor cells (Acconcia and Kumar, 2006). Similarly, PELP1 functions as a scaffold that brings together the $\mathrm{ER} \alpha$ and the signaling proteins required for the activation of the extra-nuclear E2 effects in close proximity of the plasma membrane. As in the case of MTA1s, PELP1 is over-expressed in aggressive and metastatic breast cancers (Acconcia and Kumar, 2006). Finally, the microtubule-binding protein hematopoietic PBX-interaction protein (HPIP) also contributes to E2 extranuclear signaling by recruiting the $\mathrm{ER} \alpha$ and its signaling partners in the cytoplasm of the breast cancer cells (Manavathi et al., 2006). In addition to these extra-nuclear ER $\alpha$ interactors, the de-regulation of the $\mathrm{ER} \alpha$ membrane signaling might occur as a consequence of the over-expression of specific ER $\alpha$ splice variants (e.g., ER $\alpha 36$; ER $\alpha 46$ ), which also localize into the cytoplasm or at the plasma membrane and hyper-activate the proliferative and anti-apoptotic E2 signals (Kim and Bender, 2009; Ohshiro et al., 2010).

It is, therefore, evident that the molecular circuitries, which are conserved in cell lines, are also operative in a tumor environment, and the ER $\alpha$ membrane-initiated signals are active both in nuclear $\mathrm{ER} \alpha$-positive and in nuclear $\mathrm{ER} \alpha$-negative breast tumors. Consequently, although the presence of the ER $\beta$ at the plasma membrane of tumor specimens has not yet been reported, given the high degree of conservation in both structure and mechanism of action of either ER isoforms, it is conceivable that ER $\beta$ expressing tumors also display a fraction of the receptor located at the plasma membrane. In this respect, on the basis that membrane $\mathrm{ER} \alpha$ in tumors heavily contributes to uncontrolled proliferation through the activation of the ERK/MAPK and AKT pathways (Kim et al., 2006; Kampa et al., 2008; Mintz et al., 2008), ER $\beta$ in tumor cell membrane may be associated with increased p38/MAPK activation and an increased E2-dependent apoptosis (Galluzzo et al., 2007). In support of this hypothesis, ER $\beta$ expression is lost during the progression of colon carcinoma and breast tumors expressing

\section{REFERENCES}

Acconcia, F., and Kumar, R. (2006). Signaling regulation of genomic and nongenomic non-genomic functions of estrogen receptors. Cancer Lett. 238, 1-14.

Acconcia, F., Manavathi, B., Mascarenhas, J., Talukder, A. H., Mills, G.,

ER $\beta$ have usually a better prognosis (Galluzzo et al., 2007; Barone et al., 2010).

\section{CONCLUSIONS AND PERSPECTIVES}

On the basis of the findings highlighted in this review, it is clear that the dichotomy in the ER-based signal transduction has to be overcome. Indeed, one may envisage a dynamic integrated model of action for the ERs inside the cell. In this model, ERs would trigger target gene activation by trafficking and signaling throughout the different cell compartments (i.e., cell membrane, cytoplasm, and nucleus). The cell context specific environment (e.g., ERs level and ERs co-expression) would than contribute to the synergy between the E2 rapid membrane signaling and nuclear ERs activity, thus leading to specific responses to the same hormone and thus to a different cell biological outcomes.

Although the field is moving quickly, how the membraneinitiated pathways impact on human physiology and whether these pathways are relevant to our understanding of the changes occurring during the development of hormone sensitive cancers still remains to be firmly established. In this perspective, proteomic approaches aimed at functionally classifying both the ER extranuclear interactors and the ER post-translational modifications will certainly provide a molecular map, which will help translating the many years of research in the extra-nuclear, rapid hormonal signaling field (Ascenzi et al., 2006) into the possibility of new therapeutic tools for human patho-physiology. Moreover, the definition that extra-nuclear E2 effects occurs in both animal models and tumors, besides demonstrating the complexity of the E2based signaling in vivo, further gives the opportunity to define new targets for efficacious interventions in humans.

As we gain a deeper understanding of the complex controls exerted by ER and start identifying the critical players, it is likely that some putative molecules might emerge as target candidates for therapeutic development in the treatment of hormone-related cancer. For example, the development of new estrogen receptor modulators should consider whether their actions result from binding membrane and/or nuclear ER. Thus, E2-related molecules, which target a particular receptor pool, could be efficacious, but we will have to better understand the integrative nature of their hormonal action to avoid the undesirable consequences of this approach.

\section{ACKNOWLEDGMENTS}

Some experimental concepts described in the current paper are based on work conducted in the laboratory of the authors. These experimental studies were supported by grants from the Ministry of Health (Strategico, 2008 to Maria Marino). The Authors wish to thank past and present members of their laboratory who contributed with data and discussions to the ideas presented here.

Marino, M. (2005a). Survival versus apoptotic 17ß-estradiol effect: role of ERa and ERß activated nongenomic signaling. J. Cell. Physiol. 203, 193-201.

Acconcia, F., Ascenzi, P., Bocedi, A., Spisni, E., Tomasi, V., Trentalance, A., Visca, P., and Marino, M. (2005b). Palmitoylation-dependent estrogen receptor a membrane localization: regulation by 17 B-estradiol. Mol. Biol. Cell 16, 231-237.

Acconcia, F., Totta, P., Ogawa, S., Cardillo, I., Inoue, S., Leone, S. Trentalance, A., Muramatsu, M., and
Adams, J. S. (2005). "Bound" to work: the free hormone hypothesis revisited. Cell 122, 647-649. 
Ascenzi, P., Bocedi, A., and Marino, M. (2006). Structure-function relationship of estrogen receptor a and $B$ : impact on human health. Mol. Aspect Med. 27, 299-402.

Barone, M., Scavo, M. P., Papagni, S., Piscitelli, D., Guido, R., Di Lena, M., Comelli, M. C., and Di Leo, A. (2010). ERß expression in normal, adenomatous and carcinomatous tissues of patients with familial adenomatous polyposis. Scand. J. Gastroenterol. 45, 1320-1328.

Berthois, Y., Pourreau-Schneider, N., Gandilhon, P., Mittre, H., Tubiana, N., and Martin, P. M. (1986). Estradiol membrane binding sites on human breast cancer cell lines. Use of a fluorescent estradiol conjugate to demonstrate plasma membrane binding systems. J. Steroid Biochem. 25, 963-972.

Chambliss, K. L., Wu, Q., Oltmann, S., Konaniah, E. S., Umetani, M. Korach, K. S., Thomas, G. D., Mineo, C., Yuhanna, I. S., Kim, S. H., MadakErdogan, Z., Maggi, A., Dineen, S. P., Roland, C. L., Hui, D. Y., Brekken, R. A., Katzenellenbogen, J. A., Katzenellenbogen, B. S., and Shaul, P. W. (2010). Non-nuclear estrogen receptor alpha signaling promotes cardiovascular protection but not uterine or breast cancer growth in mice. $J$. Clin. Investig. 120, 2319-2330.

De Marinis, E., Ascenzi, P., Pellegrini, M., Galluzzo, P., Bulzomi, P., Arevalo, M. A., Garcia-Segura, L. M., and Marino, M. (2010). 17 $\beta$ estradiol - a new modulator of neuroglobin levels in neurons: role in neuroprotection against $\mathrm{H} 2 \mathrm{O} 2-$ induced toxicity. Neurosignals 18, 223-235.

Deroo, B. J., and Korach, K. S. (2006). Estrogen receptors and human disease. J. Clin. Investig. 116, 561-570.

Farach-Carson, M. C., and Davis, P. J. (2003). Steroid hormone interactions with target cells: cross talk between membrane and nuclear pathways. J. Pharmacol. Exp. Therap. 307, 839-845.

Galluzzo, P., Caiazza, F., Moreno, S., and Marino, M. (2007). Role of ERß palmitoylation in the inhibition of human colon cancer cell proliferation. Endocr. Relat. Cancer 14, 153-167.

Galluzzo, P., Rastelli, C., Bulzomi, P., Acconcia, F., Pallottini, V., and Marino, M. (2009). 17ß-Estradiol regulates the first steps of skeletal muscle cell differentiation via ERamediated signals. Am. J. Physiol.Cell Physiol. 297, C1249-C1262.

Green, S., Walter, P., Kumar, V., Krust, A., Bornert, J. M., Argos, P., and Chambon, P. (1986). Human oestrogen receptor cDNA: sequence, expression and homology to verb-A. Nature 320, 134-139.

Greene, G. L., Gilna, P., Waterfield, M. Baker, A., Hort, Y., and Shine, J. (1986). Sequence and expression of human estrogen receptor complementary DNA. Science 231, 1150 1154.

Gustafsson, J.-Å. (1999). Estrogen receptor $\beta$-a new dimension in estrogen mechanism of action. J. Endocrinol. 163, 379-383.

Hammes, A., Andreassen, T. K., Spoelgen, R., Raila, J., Hubner, N., Schulz, H., Metzger, J., Schweigert, F. J., Luppa, P. B., Nykjaer, A., and Willnow, T. E. (2005). Role of endocytosis in cellular uptake of sex steroids. Cell 122, 751-762.

Hammes, S. R., and Levin, E. R. (2007). Extranuclear steroid receptors: nature and actions. Endocr. Rev. 28, 726-741.

Harrington, W. R., Kim, S. H., Funk, C. C., Madak-Erdogan, Z., Schiff, R., Katzenellenbogen, J. A., and Katzenellenbogen, B. S. (2006). Estrogen dendrimer conjugates that preferentially activate extranuclear, nongenomic versus genomic pathways of estrogen action. Mol. Endocrinol. 20, 491-502.

Herynk, M. H., and Fuqua, S. A. (2004). Estrogen receptor mutation in human disease. Endocr. Rev. 25, 869-898.

Jakacka, M., Ito, M., Martinson, F., Ishikawa, T., Lee, E. J., and Jameson, J. L. (2002). An estrogen receptor (ER)alpha deoxyribonucleic acidbinding domain knock-in mutation provides evidence for nonclassical ER pathway signaling in vivo. $\mathrm{Mol}$. Endocrinol. 16, 2188-2201.

Jensen, E. V. (1965). Mechanism of estrogen action in relation to carcinogenesis. Proc. Can. Cancer Conf 6, 143-165.

Jepsen, K., and Rosenfeld, M. G. (2002) Biological roles and mechanistic actions of co-repressor complexes. J. Cell Sci. 115, 689-698.

Kampa, M., Pelekanou, V., and Castanas, E. (2008). Membraneinitiated steroid action in breast and prostate cancer. Steroids 73, 953-960.

Keen, J. C., and Davidson, N. E. (2003). The biology of breast carcinoma. Cancer 97, 825-833.

Kim, K. H., and Bender, J. R. (2009). Membrane-initiated actions of estrogen on the endothelium. Mol. Cell. Endocrinol. 308, 3-8.

Kim, R., Kaneko, M., Arihiro, K., Emi, M., Tanabe, K., Murakami, S., Osaki, A., and Inai, K. (2006). Extranuclear expression of hormone receptors in primary breast cancer. Ann. Oncol. 17, 1213-1220.
Koduri, S., Goldhar, A. S., and Vonderhaar, B. K. (2006). Activation of vascular endothelial growth factor (VEGF) by the ERa variant, ERDelta3. Breast Cancer Res. Treat. 95, 37-43.

Kuiper, G. G., Enmark, E., Pelto-Huikko, M., Nilsson, S., and Gustafsson, J.-Å. (1996). Cloning of a novel receptor expressed in rat prostate and ovary. Proc. Natl. Acad. Sci. U.S.A 93, 5925-5930.

Kumar, R. (2003). Another tie that binds the MTA family to breast cancer. Cell 113, 142-143.

Kumar, R., Wang, R. A., Mazumdar, A. Talukder, A. H., Mandal, M., Yang, Z., Bagheri-Yarmand, R., Sahin, A., Hortobagyi, G., Adam, L., Barnes, C. J., and Vadlamudi, R. K. (2002) A naturally occurring MTA1 variant sequesters oestrogen receptoralpha in the cytoplasm. Nature 418 654-657.

Kumar, V., and Chambon, P. (1988) The estrogen receptor binds tightly to its responsive element as a ligandinduced homodimer. Cell 55, 145 156

La Rosa, P., Pesiri, V., Marino, M., and Acconcia, F. (2011). 17ß-Estradiolinduced cell proliferation requires estrogen receptor (ER) a monoubiquitination. Cell. Signal. 23, 1128 1135.

Leclercq, G., Bojar, H., Goussard, J., Nicholson, R. I., Pichon, M. F., Piffanelli, A., Pousette, A., Thorpe, S. and Lonsdorfer, M. (1986). Abbott monoclonal enzyme immunoassay measurement of estrogen receptors in human breast cancer: a European multicenter study. Cancer Res. 46, 4233s-4236s.

Lee, L. M., Cao, J., Deng, H., Chen, P., Gatalica, Z., and Wang, Z. Y. (2008). ER-a36, a novel variant of ER-a, is expressed in ER-positive and -negative human breast carcinomas. Anticancer Res. 28, 479-483.

Levin, E. R. (2009). G-protein-coupled receptor 30: estrogen receptor or collaborator? Endocrinology 150, 1563 1565.

Li, L., Haynes, M. P., and Bender, J. R. (2003). Plasma membrane localization and function of the estrogen receptor alpha variant (ER46) in human endothelial cells Proc. Natl. Acad. Sci. U.S.A. 100 4807-4812.

Lonard, D. M., and O'Malley, B. W. (2006). The expanding cosmos of nuclear receptor coactivators. Cell 125, 411-414.

Lonard, D. M., and O'Malley, B. W. (2007). Nuclear receptor coregulators: judges, juries, and executioners of cellular regulation. Mol. Cell 27, 691-700.
Losel, R. M., Falkenstein, E., Feuring, M., Schultz, A., Tillmann, H. C., Rossol-Haseroth, K., and Wehling, M. (2003). Nongenomic steroid action: controversies, questions, and answers. Physiol. Rev. 83 965-1016.

Maggiolini, M., and Picard, D. (2010). The unfolding stories of GPR30, a new membrane-bound estrogen receptor. J. Endocr. 204, 105-114.

Manavathi, B., Acconcia, F., Rayala, S. K., and Kumar, R. (2006). An inherent role of microtubule network in the action of nuclear receptor. Proc. Natl. Acad. Sci. U.S.A. 103, 15981-15986.

Marino, M., Acconcia, F., Bresciani, F., Weisz, A., and Trentalance, A. (2002). Distinct nongenomic signal transduction pathways controlled by $17 \AA$ estradiol regulate DNA synthesis and cyclin $\mathrm{D}(1)$ gene transcription in HepG2 cells. Mol. Biol. Cell 13, 3720-3729.

Marino, M., Acconcia, F., and Trentalance, A. (2003). Biphasic estradiolinduced AKT phosphorylation is modulated by PTEN via MAP kinase in HepG2 cells. Mol. Biol. Cell 14, 2583-2591

Marino, M., and Ascenzi, P. (2008) Membrane association of estrogen receptor a and $B$ influences $17 \AA$ estradiol-mediated cancer cell proliferation. Steroids 73, 853-858.

Márquez, D. C., Chen, H. W., Curran, E M., Welshons, W. V., and Pietras, R. J. (2006). Estrogen receptors in membrane lipid rafts and signal transduction in breast cancer. Mol. Cell. Endocrinol. 246, 91-100.

McKenna, N. J., and O’Malley, B. W. (2001). Nuclear receptors, coregulators, ligands, and selective receptor modulators: making sense of the patchwork quilt. Ann. N. Y. Acad. Sci. 949, 3-5.

Medunjanin, S., Hermani, A., De Servi, B., Grisouard, J., Rincke, G., and Mayer, D. (2005). Glycogen synthase kinase-3 interacts with and phosphorylates estrogen receptor alpha and is involved in the regulation of receptor activity. J. Biol. Chem. 280, 33006-33014.

Métivier, R., Penot, G., Hübner, M. R., Reid, G., Brand, H., Kos, M. and Gannon, F. (2003). Estrogen receptor-alpha directs ordered, cyclical, and combinatorial recruitment of cofactors on a natural target promoter. Cell 115, 751-763.

Mintz, P. J., Habib, N. A., Jones, L. J. Giamas, G., Lewis, J. S., Bowen, R. L., Coombes, R. C., and Stebbing, J. (2008). The phosphorylated membrane estrogen receptor and cytoplasmic signaling and apoptosis proteins in human breast cancer. Cancer 113, 1489-1495. 
Murphy, L. C., Seekallu, S. V., and Watson, P. H. (2011). Clinical significance of estrogen receptor phosphorylation. Endocr. Relat. Cancer 18, R1-R14.

Nalvarte, I., Schwend, T., and Gustafsson, J.-̊̊. (2010). Proteomics analysis of the estrogen receptor alpha receptosome. Mol. Cell Proteomics 9, 1411-1422.

Nilsson, S., and Gustafsson, J.-̊̊. (2011). Estrogen receptors: therapies targeted to receptor subtypes. Clin. Pharmacol. Ther. 89, 44-55.

Norfleet, A. M., Thomas, M. L., Gametchu, B., and Watson, C. S. (1999). Estrogen receptor-alpha detected on the plasma membrane of aldehyde-fixed GH3/B6/F10 rat pituitary tumor cells by enzymelinked immunocytochemistry. Endocrinology 140, 3805-3814.

Ohshiro, K., Mudvari, P., Meng, Q. C., Rayala, S. K., Sahin, A. A., Fuqua, S. A., and Kumar, R. (2010). Identification of a novel estrogen receptoralpha variant and its upstream splicing regulator. Mol. Endocrinol. 24, 914-922.

O'Malley, B. W., and Kumar, R. (2009). Nuclear receptor coregulators in cancer biology. Cancer Res. 69, 82178222.

O'Malley, B. W., and McGuire, W. L. (1968). Studies on the mechanism of estrogen-mediated tissue differentiation: regulation of nuclear transcription and induction of new RNA species. Proc. Natl. Acad. Sci. U.S.A. 60, 1527-1534.

Otto, C., Fuchs, I., Kauselmann, G., Kern, H., Zevnik, B., Andreasen, P., Schwarz, G., Altmann, H., Klewer, M., Schoor, M., Vonk, R., and Fritzemeier, K. H. (2009). GPR30 does not mediate estrogenic responses in reproductive organs in mice. Biol. Reprod. 80, 34-41.

Pappas, T. C., Gametchu, B., and Watson, C. S. (1995). Membrane estrogen receptors identified by multiple antibody labeling and impededligand binding. FASEB J. 9, 404-410.

Paruthiyil, S., Parmar, H., Kerekatte, V., Cunha, G. R., Firestone, G. L., and Leitman, D. C. (2004). Estrogen receptor beta inhibits human breast cancer cell proliferation and tumor formation by causing a G2 cell cycle arrest. Cancer Res. 64, 423-428.

Pearce, S. T., and Jordan, V. C. (2004). The biological role of estrogen receptors alpha and beta in cancer. Crit. Rev. Oncol. Hematol. 50, 3-22.
Pedram, A., Razandi, M., Kim, J. K., O'Mahony, F., Lee, E. Y., Luderer, U., and Levin, E. R. (2009). Developmental phenotype of a membrane only estrogen receptor alpha (MOER) mouse. J. Biol. Chem. 284, 3488-3495.

Pedram, A., Razandi, M., and Levin, E. R. (2006). Nature of functional estrogen receptors at the plasma membrane. Mol. Endocrinol. 20, 1996-2009.

Pelekanou, V., Kampa, M., Gallo, D., Notas, G., Troullinaki, M., Duvillier, H., Jacquot, Y., Stathopoulos, E. N., Castanas, E., and Leclercq, G. (2011). The estrogen receptor alphaderived peptide ERa17p [P(295)$\mathrm{T}(311)]$ exerts pro-apoptotic actions in breast cancer cells in vitro and in vivo, independently from their ERa status. Mol. Oncol. 5, 36-47.

Penot, G., Le Péron, C., Mérot, Y., Grimaud-Fanouillère, E., Ferrière, F., Boujrad, N., Kah, O., Saligaut, C., Ducouret, B., Métivier, R., and Flouriot, G. (2005). The human estrogen receptor-alpha isoform hERalpha46 antagonizes the proliferative influence of hERalpha66 in MCF7 breast cancer cells. Endocrinology 146, 5474-5484.

Picard, N., Charbonneau, C., Sanchez, M., Licznar, A., Busson, M., Lazennec, G., and Tremblay, A. (2008). Phosphorylation of activation function-1 regulates proteasomedependent nuclear mobility and E6-associated protein ubiquitin ligase recruitment to the estrogen receptor beta. Mol. Endocrinol. 22, 317-330.

Pietras, R. J., and Szego, C. M. (1977). Specific binding sites for oestrogen at the outer surfaces of isolated endometrial cells. Nature 265, 69-72.

Pietras, R. J., and Szego, C. M. (1984). Specific internalization of estrogen and binding to nuclear matrix in isolated uterine cells. Biochem. Biophys. Res. Commun. 123, 84-91.

Prossnitz, E. R., Arterburn, J. B., Smith, H. O., Oprea, T. I., Sklar, L. A., and Hathaway, H. J. (2008). Estrogen signaling through the transmembrane $G$ protein-coupled receptor GPR30. Ann. Rev. Physiol. 70, 165-190.

Razandi, M., Alton, G., Pedram, A., Ghonshani, S., Webb, P., and Levin, E. R. (2003). Identification of a structural determinant necessary for the localization and function of estrogen receptor alpha at the plasma membrane. Mol. Cell. Biol. 23, 1633-1646.

Razandi, M., Oh, P., Pedram, A., Schnitzer, J., and Levin, E. R. (2002). ERs associate with and regulate the production of caveolin: implications for signaling and cellular actions. Mol. Endocrinol. 16, 100-115.

Razandi, M., Pedram, A., Greene, G. L., and Levin, E. R. (1999). Cell membrane and nuclear estrogen receptors (ERs) originate from a single transcript: studies of ERalpha and ERbeta expressed in Chinese hamster ovary cells. Mol. Endocrinol. 13 307-319.

Reid, G., Hübner, M. R., Métivier, R. Brand, H., Denger, S., Manu, D. Beaudouin, J., Ellenberg, J., and Gannon, F. (2003). Cyclic, proteasomemediated turnover of unliganded and liganded ERalpha on responsive promoters is an integral feature of estrogen signaling. Mol. Cell 11, 695-707.

Safe, S. (2001). Transcriptional activation of genes by 17 betaestradiol through estrogen receptorSp1 interactions. Vitam. Horm. 62, 231-252.

Sanchez, A. M., Flamini, M. I., Fu, X. D. Mannella, P., Giretti, M. S., Goglia, L., Genazzani, A. R., and Simoncini, T. (2009). Rapid signaling of estrogen to WAVE1 and moesin controls neuronal spine formation via the actin cytoskeleton. Mol. Endocrinol. 23, 1193-1202.

Scheidt, H. A., Badeau, R. M., and Huster, D. (2010). Investigating the membrane orientation and transversal distribution of 17beta-estradiol in lipid membranes by solid-state NMR. Chem. Phys. Lipid 163, 356-361.

Simoncini, T., Hafezi-Moghadam A., Brazil, D. P., Ley, K. Chin, W. W., and Liao, J. K. (2000). Interaction of oestrogen receptor with the regulatory subunit of phosphatidylinositol$3-\mathrm{OH}$ kinase. Nature 407 538-541.

Song, R. X., Barnes, C. J., Zhang, Z., Bao, Y., Kumar, R., and Santen, R. J. (2004). The role of Shc and insulin-like growth factor 1 receptor in mediating the translocation of estrogen receptor alpha to the plasma membrane. Proc. Natl. Acad. Sci. U.S.A. 101, 2076-2081.
Szego, C. M., and Davis, J. S. (1967). Adenosine 3(,5(-monophosphate in rat uterus: acute elevation by estrogen. Proc. Natl. Acad. Sci. U.S.A. 58, 1711-1718.

Wang, Z., Zhang, X., Shen, P., Loggie, B. W., Chang, Y., and Deuel, T. F. (2005). Identification, cloning, and expression of human estrogen receptor-alpha36, a novel variant of human estrogen receptor-alpha66. Biochem. Biophys. Res. Commun. 336, 1023-1027.

Wang, Z., Zhang, X., Shen, P., Loggie, B. W., Chang, Y., and Deuel, T. F. (2006). A variant of estrogen receptor-a, hER-a36: transduction of estrogen- and antiestrogendependent membrane-initiated mitogenic signaling. Proc Natl. Acad. Sci. U.S.A. 103 9063-9068.

Warner, M., and Gustafsson, J.-Å. (2010). The role of estrogen receptor beta (ERbeta) in malignant diseases-a new potential target for antiproliferative drugs in prevention and treatment of cancer. Biochem. Biophys. Res. Commun. 396 63-66.

Yang, Z., Barnes, C. J., and Kumar, R. (2004). Human epidermal growth factor receptor 2 status modulates subcellular localization of and interaction with estrogen receptor alpha in breast cancer cells. Clin. Cancer Res. 10, 3621-3628.

Conflict of Interest Statement: The authors declare that the research was conducted in the absence of any commercial or financial relationships that could be construed as a potential conflict of interest.

Received: 28 April 2011; accepted: 17 June 2011; published online: 30 June 2011.

Citation: Acconcia $F$ and Marino $M$ (2011) The effects of 173-estradiol in cancer are mediated by estrogen receptor signaling at the plasma membrane. Front. Physio. 2:30. doi: 10.3389/fphys.2011.00030

This article was submitted to Frontiers in Membrane Physiology and Biophysics, a specialty of Frontiers in Physiology.

Copyright $\odot 2011$ Acconcia and Marino. This is an open-access article subject to a non-exclusive license between the authors and Frontiers Media SA, which permits use, distribution and reproduction in other forums, provided the original authors and source are credited and other Frontiers conditions are complied with 